\section{A Case of Pulmonary Arteriovenous Fistula}

\author{
[With Special Plate]
}

The condition of pulmonary arteriovenous fistula was first recognized clinically by Smith and Horton in 1939, and has now been established in some 31 published cases. The case here reported merits record because of the lack of symptoms.

Most cases described in the literature have presented either with a haemoptysis or evidence of a considerable " right-to-left" vascular shunt. A vascular murmur has been heard in about half the cases, while multiple haemangiomata have been noted in a similar proportion. Radiologically, the condition presents as a pulmonary shadow of irregular density and shape, the vascular nature of which can be demonstrated by cardioangiography. The more dramatic presentation of patients with cyanosis, polycythaemia, and clubbing of the fingers, and their response to operation, may mean that the literature does not give a true indication of the incidence of cases with a symptomless degree of shunt

Whitaker (1947) describes a symptomless case presenting with a typical murmur and having multiple facial telangiectasia. Another case described by Duvoir et al. (1939) was that of a girl, aged 17 , suffering from congenital syphilis and with a complaint of attacks of nocturnal dyspnoea. She died from pneumonia, and necropsy revealed a haemangioma occupying the whole of the left lower lobe, together with similar lesions in other viscera, multiple lipomata, and bilateral congenital defects of the hands.

Beddard (1949) and Duisenberg and Arismendi (1949) report pulmonary haemangiomata presenting as a haemoptysis, the characteristic murmur being absent in the latter's case. A case of a 2-day-old male infant who died from rupture of one of a number of subpleural haemangiomata is described by Bowers (1936). It has been suggested by Maier et al. (1948) that such cases without significant shunts are due to the involvement of the bronchial circulatory system.

The treatment of the condition is by resection of the haemangiomata, either locally or by lobectomy, and in some cases pneumonectomy. Operation is certainly indicated in patients who have had a haemoptysis or have significant shunt. The symptomless case presents a more difficult problem, the operative risk having to be weighed against the risk of future haemorrhagic episodes or an increase in the degree of right-to-left shunt. There would also seem to be the risk of the development of bacterial endarteritis in the wall of the aneurysm (Maier et al., 1948).

\section{Case Report}

A sapper aged 18 was admitted to hospital on March 28, 1950 , for investigation of an abnormal thoracic shadow found on routine mass miniature radiography. A full-size film was then reported upon thus: "A mottled opacity is present in the right fourth and fifth costal regions anteriorly. Fairly dense, and outline irregular." (Plate, Fig. 1.) Lateral films indicated that the opacity was in the right middle lobe (Fig. 2).

The patient had no complaints, but stated that on running he developed dyspnoea more readily than his fellows and experienced a tight feeling in the upper chest. He had at no time had a haemoptysis and was otherwise symptom-free. His school and games records were average, and there was no family history suggestive of vascular abnormalities.
On examination he was seen to be small and rather poorly developed, being $5 \mathrm{ft} .6 \frac{1}{4}$ in. $(170 \mathrm{~cm}$.) in height and weighing $114 \mathrm{lb}$. (51.7 kg.). His facial and mucosal colour was normal, but his hands were rather cold and slightly cyanotic. There was no finger-clubbing. The pulse rate was 74 a minute, with a normal tension in both radial and femoral arteries, the brachial blood pressure being $115 / 75$. The cardiac apex was $3 \frac{1}{4}$ in. $(8.25 \mathrm{~cm}$.) from the midline in the fifth left intercostal space, auscultation being normal.

Examination of the chest revealed a loud vascular murmur, with systolic and diastolic elements, in the third, fourth, and fifth right costal regions outside the midclavicular line. It was maximal just lateral to the nipple and conducted to the axilla, being at maximum intensity on full inspiration. The murmur also varied with posture, being loudest when standing or lying on the left side, and was accompanied by a barely perceptible thrill.

The respiratory system was otherwise normal, and routine examination of the gastro-intestinal and nervous systems revealed no abnormality. Careful search failed to reveal cutaneous, mucosal, or other visceral angiomata.

Investigations. - Radiological screening revealed " no pulsation of the opacity or increased hilar pulsation." Angiocardiography "shows an angiomatous condition of the vessels of the right middle lobe" (Fig. 3). A blood count showed: red cells, 5,490,000; haemoglobin, $100 \%$. 14.8 g. \% (Haldane); colour index, 0.9 ; white cells, 8,300 (polymorphs $66 \%$, lymphocytes $25 \%$, mononuclears $7 \%$, eosinophils $2 \%$, basophils $0 \%$ ). The Wassermann reaction was negative ; E.S.R., $5 \mathrm{~mm}$. in one hour (Westergren). An electrocardiogram "showed normal deflections in limb and chest leads." Cardiac catheterization "shows a small rightto-left shunt in the pulmonary circulation." Exercise tolerance test: "Normal tolerance; the blood pressure showed the normal reactions to exercise." Circulation time: ether (arm-lung), 9 seconds; saccharin (arm-tongue), 13 seconds.

These investigations confirm the diagnosis of an angiomatous arteriovenous fistula of the pulmonary circulation with only a small right-to-left shunt.

After careful consideration it was felt that as the patient was virtually asymptomatic operation was not indicated, but that he should be kept under medical surveillance.

I would like to thank Dr. A. V. Gardner and his staff of the Royal Free Hospital, London, for the angiocardiography, the cardiac catheterization, and their helpful opinions; Major J. S. cardiac catheterization, and their helpful opinions; Major J. S. Colonel L. Handy, Officer Commanding, Cambridge Hospital, Aldershot, for permission to publish the case.

J. A. Nightingale, M.B., Ch.B., M.R.C.P. Captain, R.A.M.C., Junior Specialist in Medicine.

\section{REFERENCES}

Beddard, F. D. (1949). British Medical Journal, 1, 1038. Bowers, W. F. (1936). Neb. St. med. J., 21, 55.

Duisenberg, C. E., and Arismendi, L. (1949). Radiology, 53, 66. Duvoir, M., Picot, G., Pollet, L., and Gaultier, M. (1939). Bull. Soc. méd. Hôp. Paris, 55, 596.

Maier, H. C., Himmelstein, A., Riley, R. L., and Bunin, J. J. (1948). J. thorac. Surg., 17, 13.

Smith, H. L., and Horton, B. T. (1939). Amer. Heart J., 18, 589.

Whitaker, W. (1947). Thorax, 2, 58.

D.N.C. (dinitro-ortho-cresol) weed-killer caused the death of an agricultural worker who did not wear the mask, rubber gloves, and rubber boots provided to protect him (News Chronicle, July 25). The day was hot, and he wore only a boiler suit and ordinary shoes. Dr. R. A. A. Galley, of the Agricultural Research Council, stated at the inquest that if all the recommended precautions and clothing were adopted when handling the concentrate little danger was incurred. 


\section{P. ELLMAN AND A. GEE (contd.)}

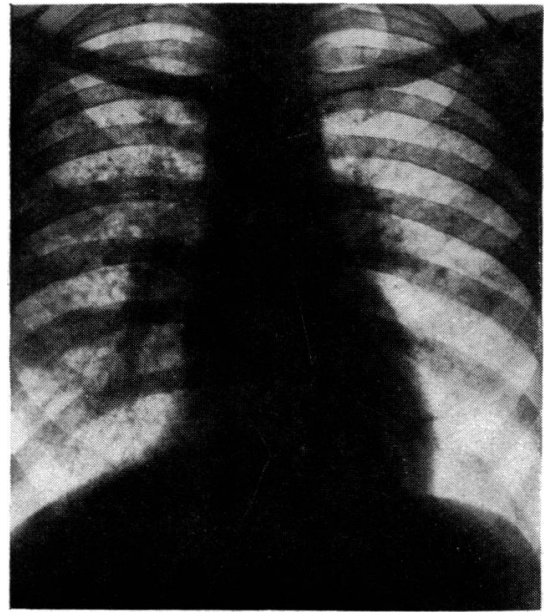

Fig. 7.-Skiagram of Case 5 in February, 1948.

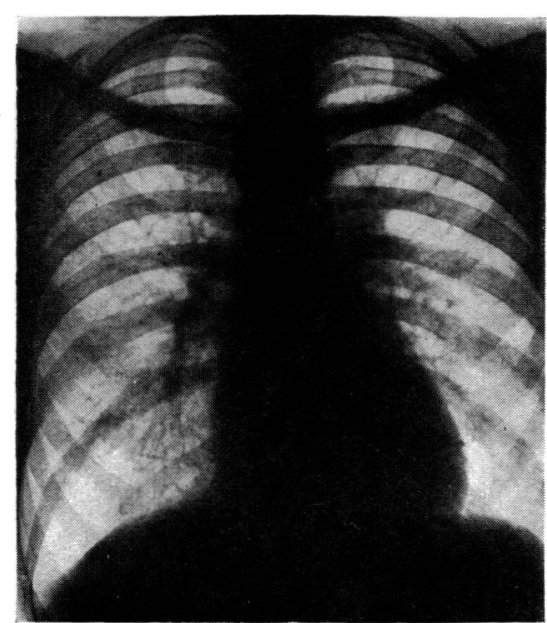

FIG. 8.-Skiagram of Case 5 in 1950. Resolution of miliary opacities in righ lung and middle zone of left lung.
J. E. CATES AND

M. B. MCILROY :

TRYPANOSOMIASIS

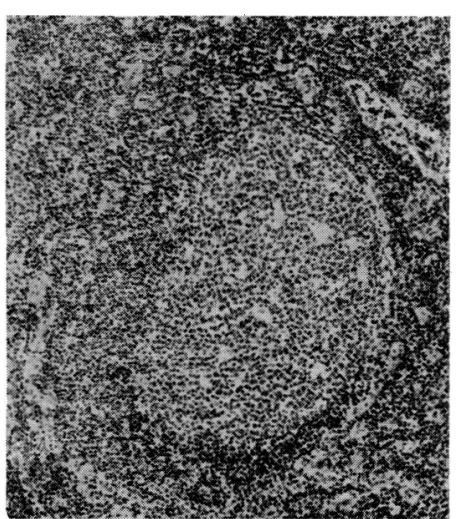

Fig. 1.-Photomicrograph of section of cervical lymph node in trypanosomiasis. $(\times 75$.

\section{R. CASTEX AND E. MAZZEI: EMPHYSEMATOUS-BULlOUS FORM OF BRONCHIAL CANCER}

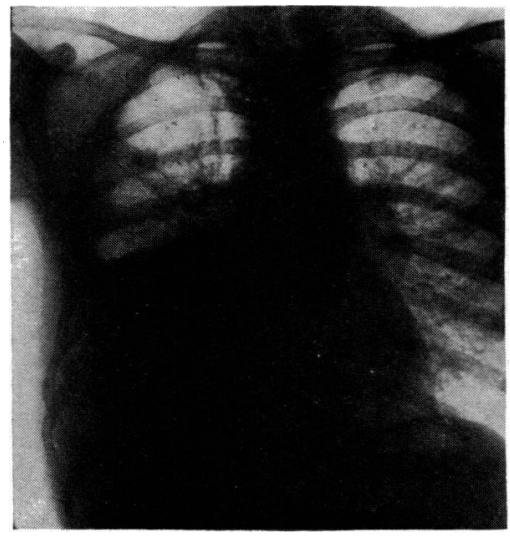

FIG: 1.

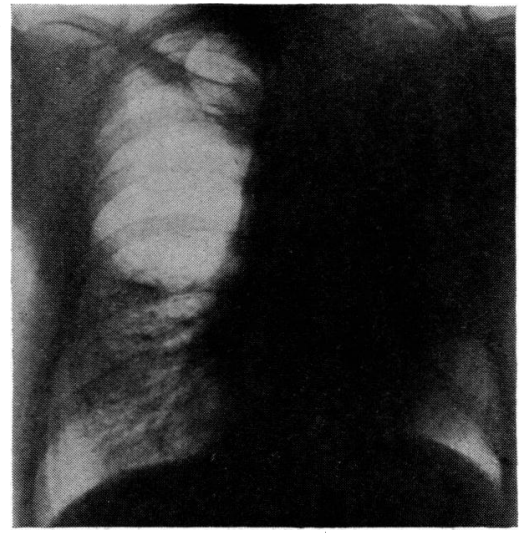

FIG. 2.

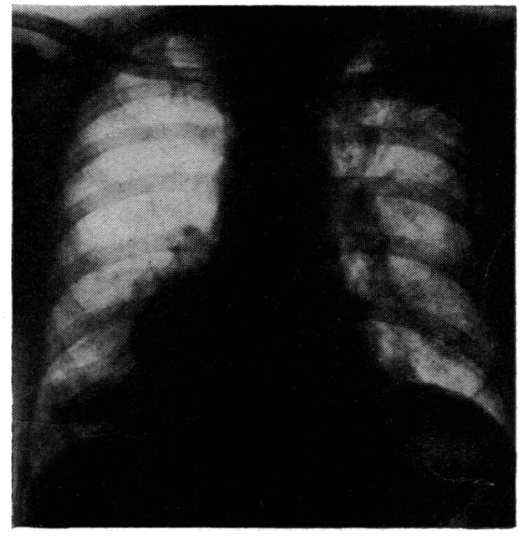

FIG. 3.

\section{J. A. NIGHTINGALE: PULMONARY ARTERIOVENOUS FISTULA}

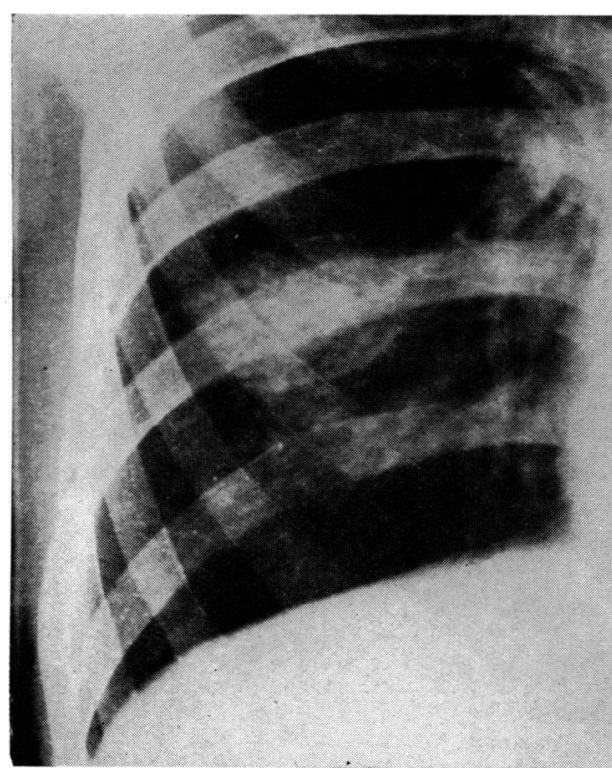

FIG. 1.-Postero-anterior film of chest.

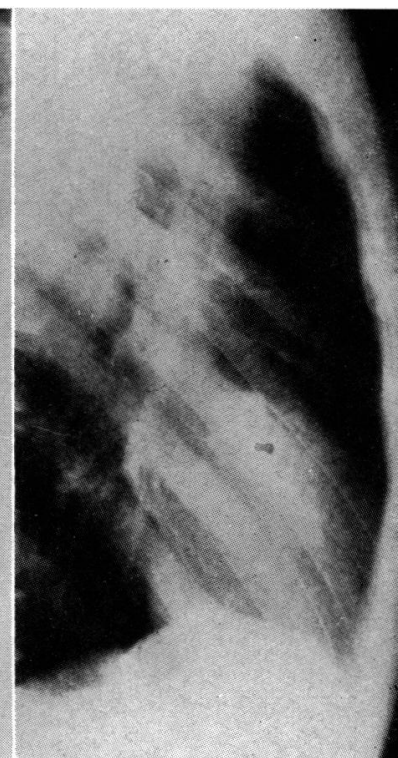

FIg. 2.-Right lateral film of chest.

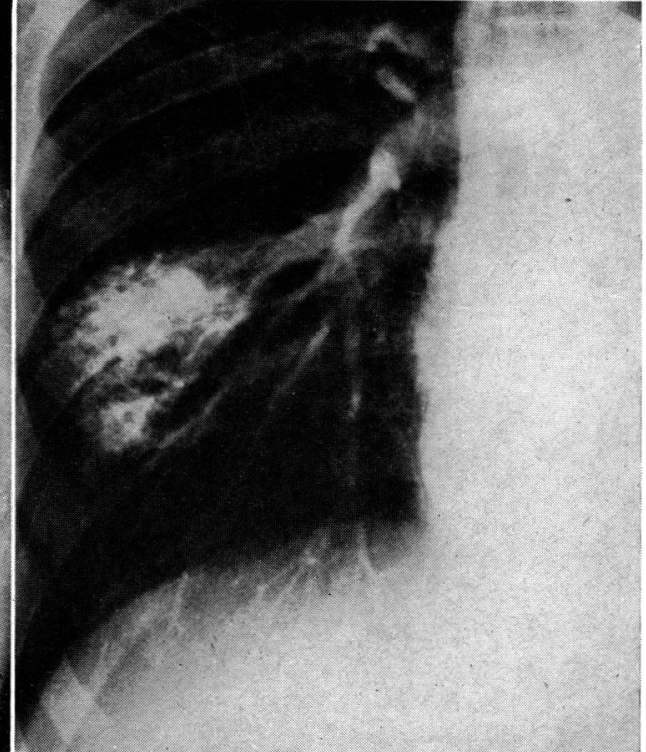

FIG. 3.-Angiocardiogram-2-second film. 